\title{
Effect of different loading doses of atorvastatin on percutaneous coronary intervention for acute coronary syndromes
}

\author{
Yujiao Sun MMed, Guoxian Qi MD, Yuan Gao MD, Haishan Zhang MD, Xuefeng Pang MD, \\ Weihua Zhao MD, Zixin Zhang MD
}

Y Sun, G Qi, Y Gao, et al. Effect of different loading doses of atorvastatin on percutaneous coronary intervention for acute coronary syndromes. Can J Cardiol 2010;26(9):481-485.

BACKGROUND: Percutaneous coronary intervention (PCI)-induced myocardial damage is associated with late cardiovascular events. Treatment with atorvastatin before PCI can reduce myocardial damage during the peri-PCI period.

OBJECTIVES: To compare the safety and myocardial effects of different atorvastatin loading doses and dosing frequency before PCI in non-ST segment elevation acute coronary syndrome (NSTE-ACS) patients.

METHODS: Eighty NSTE-ACS patients were randomly divided into four groups (20 patients per group). The control group was given $40 \mathrm{mg}$ atorvastatin each night. The three loading dose groups were treated the same as in the control group, but were given $80 \mathrm{mg}$ atorvastatin $12 \mathrm{~h}$ before PCI (lowload group) in combination with $40 \mathrm{mg}$ atorvastatin $2 \mathrm{~h}$ to $4 \mathrm{~h}$ before PCI (mid-load group) or $60 \mathrm{mg}$ atorvastatin $2 \mathrm{~h}$ to $4 \mathrm{~h}$ before PCI (high-load group). All patients underwent PCI within $48 \mathrm{~h}$ to $72 \mathrm{~h}$ of admission, and received $40 \mathrm{mg}$ atorvastatin for at least one month after PCI. Changes in myocardial markers and highly sensitive C-reactive protein were analyzed. Patients were followed up for 30 days to monitor the incidence of major adverse cardiac events (MACE).

RESULTS: No deaths or revascularizations were recorded. The incidences of MACE differed significantly between the four groups (40\%, 25\%, 10\% and $0 \%$ for the control, low-load, mid-load and high-load groups, respectively; $\mathrm{P}<0.05)$. The incidence of MACE and cardiac troponin I level above the normal range, and post-PCI increases in creatine kinase-MB and highly sensitive $\mathrm{C}$-reactive protein were significantly higher in the control group than in the high-load group (all $\mathrm{P}<0.007$ ). The post-PCI alanine aminotransferase levels in all four groups were significantly higher than the pre-PCI levels, but were within normal ranges. No myalgia or myasthenia was observed.

CONCLUSION: The results of the present study show that short-term atorvastatin loading before PCI was well tolerated and had beneficial myocardial effects in patients with NSTE-ACS.

Key Words: Atorvastatin; Interventional therapy; Non-ST segment elevation acute coronary syndrome

\section{L'effet de différentes doses d'attaque d'atorvastatine sur les interventions coronaires percutanées en cas de syndrome coronarien aigu}

\begin{abstract}
HISTORIQUE : Les atteintes myocardiques induites par une intervention coronaire percutanée (ICP) s'associent à des événements cardiovasculaires tardifs. Un traitement à l'atorvastatine avant l'ICP peut réduire l'atteinte myocardique pendant la période entourant l'ICP.

OBJECTIFS : Comparer l'innocuité et les effets myocardiques de diverses doses d'attaque d'atorvastatine et la fréquence des doses avant l'ICP chez des patients ayant un syndrome coronarien aigu sans élévation du segment ST (SCA-SÉST).
\end{abstract}

MÉTHODOLOGIE : Quatre-vingts patients ayant un SCA-SÉST ont été aléatoirement divisés en quatre groupes (20 patients par groupe). Le groupe témoin a reçu $40 \mathrm{mg}$ d'atorvastatine chaque nuit. Les trois groupes recevant une dose d'attaque étaient traités de la même façon que le groupe témoin, mais le groupe à faible dose d'attaque a reçu $80 \mathrm{mg}$ d'atorvastatine 12 heures avant l'ICP, auxquels s'ajoutaient $40 \mathrm{mg}$ d'atorvastatine de deux à quatre heures avant l'ICP dans le groupe à dose d'attaque moyenne, et $60 \mathrm{mg}$ d'atorvastatine de deux à quatre heures avant l'ICP dans le groupe à forte dose d'attaque. Tous les patients ont subi une ICP dans les 48 à 72 heures suivant leur hospitalisation et ont reçu $40 \mathrm{mg}$ d'atorvastatine pendant au moins un mois après l'ICP. Les chercheurs ont analysé les modifications aux marqueurs myocardiques et la protéine $\mathrm{C}$ réactive à haute sensibilité. Les patients ont été suivis pendant une période maximale de 30 jours pour surveiller l'incidence d'événements cardiaques indésirables majeurs (ÉCIM).

RÉSULTATS : Aucun décès et aucune revascularisation n'ont été consignés. L'incidence d'ÉCIM différait considérablement entre les quatre groupes $(40 \%, 25 \%, 10 \%$ et $0 \%$ dans les groupes témoin, à faible dose, à dose moyenne et à forte dose, respectivement; $\mathrm{P}<0,05)$. L'incidence d'ÉCIM et le taux de troponine I cardiaque au-dessus de la plage normale et les augmentations de créatine-kinase- $\mathrm{MB}$ et de protéine $\mathrm{C}$ réactive à haute sensibilité après l'ICP étaient considérablement plus élevés dans le groupe témoin que dans le groupe à forte dose (tous les $\mathrm{P}<0,007$ ). Les taux d'alanine aminotransférase après l'ICP dans les quatre groupes étaient beaucoup plus élevés qu'avant l'ICP, mais demeuraient dans les plages normales. On n'a constaté aucune myalgie ou myasthénie.

CONCLUSIONS : Les résultats de la présente étude démontrent que la dose d'attaque d'atorvastatine à court terme avant l'ICP était bien tolérée et avait des effets myocardiques bénéfiques chez les patients ayant un SCASÉST.

Atorvastatin for Reduction of Myocardial Damage During Angioplasty (ARMYDA) (2), ARMYDA-Acute Coronary Syndromes (ARMYDAACS) (3) and ARMYDA-RECAPTURE (4), have shown that treatment with loading atorvastatin before PCI can significantly reduce PCI-induced myocardial damage. However, no randomized controlled studies have investigated the effects of atorvastatin treatment (including loading dose and frequency) or whether short-term in-hospital atorvastatin treatment is effective for patients with non-ST segment elevation acute coronary syndromes (NSTE-ACS).
Dercutaneous coronary intervention $(\mathrm{PCI})$ is now a commonly used revascularization treatment for coronary artery disease. However, although PCI restores blood flow to the heart, it may cause myocardial damage, which is associated with late cardiovascular events (1). Statin drugs, since their introduction in the 1980s, have become the first-choice lipid-lowering therapy and are useful in preventing coronary artery disease. Many studies have found that statins have beneficial pleiotropic cardiovascular effects in addition to their lipid-lowering effects. A number of clinical trials, including
Department of Cardiology, The First Affiliated Hospital of China Medical University, Shenyang, China

Correspondence and reprints: Dr Guoxian Qi, Department of Cardiology, The First Affiliated Hospital of China Medical University, NO.155 Nanjing

North Street, Heping Ward, Shenyang 110001, China. Telephone 24-83282226, fax 24-83282226, e-mail qigx2002@medmail.com.cn

Received for publication April 23, 2010. Accepted June 8, 2010 


\section{METHODS}

Research subjects and study design

Research subjects were randomly recruited between October 2009 and March 2010 from inpatients at the Department of Cardiology of the First Affiliated Hospital of China Medical University (Shenyang, China). The study was approved by the ethical committee at The First Affiliated Hospital, and all patients provided informed consent. The patients were included if they presented with NSTE-ACS and were scheduled to undergo PCI within $48 \mathrm{~h}$ to $72 \mathrm{~h}$ of admission. Patients who met any of the following criteria were excluded: presented with ST segment elevation acute myocardial infarction; presented with high-risk NSTE-ACS requiring emergency PCI; were already on statin therapy or had a history of statin therapy in the previous two months; had a left ventricular ejection fraction below $30 \%$; or had a history of hemorrhage, major surgery, severe renal/hepatic insufficiency, muscular disorders, infectious diseases, autoimmune diseases, a malignant tumour or other contraindications to statin therapy.

A total of 163 patients met the inclusion criteria, but 49 of these also met one or more exclusion criteria and were excluded, including 10 patients already treated with statins, eight with severe left ventricular dysfunction, 23 with severe hepatic or renal insufficiency, five with a history of hemorrhage or major surgery within the past six months, and three high-risk patients who required emergency PCI. Of the remaining 114 patients, four did not provide signed, informed consent and were excluded. After coronary angiography, 30 patients were excluded (17 subsequently underwent surgical bypass and 13 continued medication). Thus, a total of 80 patients who underwent stent implantation were enrolled as subjects in the present study. The patients were randomly divided into four groups ( $\mathrm{n}=20$ per group) using a random number table. The groups were a control group, a low-load group, a mid-load group and a high-load group. The control group was given $40 \mathrm{mg}$ atorvastatin each night. The three loading dose groups were treated the same as in the control group, but were given $80 \mathrm{mg}$ atorvastatin $12 \mathrm{~h}$ before PCI (low-load group) in combination with $40 \mathrm{mg}$ atorvastatin $2 \mathrm{~h}$ to $4 \mathrm{~h}$ before PCI (mid-load group) or $60 \mathrm{mg}$ atorvastatin $2 \mathrm{~h}$ to $4 \mathrm{~h}$ before PCI (high-load group). The operators and clinical staff involved in patient follow-up were blinded to the treatment assigned.

All subjects underwent standard PCI via radial artery puncture. All subjects were given oral acetylsalicylic acid $(100 \mathrm{mg} /$ day or $300 \mathrm{mg} /$ day $)$ and clopidogrel (75 mg/day) daily, with an accumulated dose of at least $300 \mathrm{mg}$ before PCI. In some cases, glycoprotein IIb/IIIa receptor antagonists were administered during PCI as deemed necessary by the operators. The PCI operation was considered to be successful if the post-PCI residual stenosis was below 30\%. After PCI, the patients were to be treated with low molecular weight heparin for three to five days, clopidogrel for at least 12 months, atorvastatin (40 mg every night) for at least one month, and acetylsalicylic acid for life. In addition, patients without contraindications were given beta-receptor antagonists, and angiotensin-converting enzyme inhibitors, antagonists or receptor blockers.

Venous blood samples were collected from each patient at three time points (before PCI, $8 \mathrm{~h}$ after PCI and $24 \mathrm{~h}$ after PCI). The creatine kinase-MB (CK-MB) level was assayed using a dry chemical method, cardiac troponin I (cTnI) by chemiluminescence, and highly sensitive C-reactive protein (hs-CRP) by scatter turbidimetry. The normal ranges of CK-MB, cTnI and hs-CRP levels were considered to be $16 \mathrm{ng} / \mathrm{mL}$ or less, $0.4 \mathrm{ng} / \mathrm{mL}$ or less, and $0 \mathrm{mg} / \mathrm{L}$ to $3 \mathrm{mg} / \mathrm{L}$, respectively.

\section{End point events}

The primary end point events included major adverse cardiac events (MACE) that occurred within 30 days after PCI including cardiac death, myocardial infarction and revascularization treatment. Myocardial infarction in patients with normal pre-PCI levels was defined by the post-PCI levels of a cardiac marker (CK-MB or cTnI) reaching $300 \%$ of the normal upper limit. In patients whose pre-PCI levels were beyond the normal ranges, myocardial infarction was defined by the post-PCI level of a marker reaching $300 \%$ of its baseline level before PCI (5). Revascularization treatment included secondary PCI or coronary artery bypass grafting of the target vessel.

Secondary end point events included the following:

1. The cardiac marker levels in a patient were within the normal ranges before $\mathrm{PCI}$, but increased beyond the normal range after $\mathrm{PCI}$, or the pre-PCI cardiac marker levels in a patient were beyond the normal ranges and increased further after PCI.

2. The post-PCI hs-CRP level was higher than the pre-PCI level.

\section{Statistical analyses}

Continuous data are expressed as means \pm SDs, and were analyzed by ANOVA. The least significant difference $t$ test was used for multiple comparisons. Categorical data are expressed as n (\%), and were analyzed by $\chi^{2}$ tests. $\mathrm{P}<0.05$ was considered to be statistically significant. Pairwise multiple comparisons were performed by $\chi^{2}$ partitioning with a significance level $(\alpha$ ') of 0.007. All analyses were performed using SPSS version 14.0 (SPSS Inc, USA).

\section{RESULTS}

Clinical and procedural features in the four groups are reported in Tables 1 and 2. The four groups had similar baseline characteristics including age, sex, body mass index, history of disease, clinical conditions, left ventricular ejection fraction, in-hospital medication, angiographic features and nature of operation (all $\mathrm{P}>0.05$ ). All patients were successfully treated by implantation of drug-eluting stents.

No deaths or revascularizations were recorded during the follow-up, and the incidence of myocardial infarction was equivalent to the overall rate of MACE. The incidence of MACE within 30 days after PCI was significantly different among the four groups (40\%, 25\%, 10\% and $0 \%$ for the control, low-load, mid-load and high-load groups, respectively; $\mathrm{P}<0.05)$ and was significantly lower in the high-load group than in the control group $(\mathrm{P}<0.007)$. The differences between other pairs of groups were not statistically significant, but the incidence of MACE showed a decreasing trend with increasing loading dose (Table 3).

Before PCI, the proportions of patients with levels of myocardial markers above the upper limit of the normal range were similar in the four groups. After PCI, this proportion was higher than the pre-PCI value in the control group $(\mathrm{P}<0.05)$ but remained similar to the pre-PCI value in the three groups that received a loading dose of atorvastatin. In addition, the four groups showed statistically significant differences in the proportion of patients with post-PCI cTnI levels above the upper limit of the normal range $(80 \%, 60 \%, 45 \%$ and $35 \%$ for the control, low-load, mid-load and high-load groups, respectively; $\mathrm{P}<0.05$ ). Compared with the control group, the proportion of patients with postPCI CK-MB or cTnI levels above their respective upper limits was significantly lower in the high-load group $(\mathrm{P}<0.007)$. The proportion of patients with post-PCI levels of myocardial markers above the upper limit of the normal range decreased with increasing frequency and dose of atorvastatin treatment (Table 4). The proportion of patients with above-baseline levels of hs-CRP post-PCI was not significantly different among the four groups ( $75 \%, 60 \%, 50 \%$ and $25 \%$, respectively; $P>0.05$ ), although the proportion was significantly lower in the high-load dose group than in the control group based on $\chi^{2}$ partitioning $(\mathrm{P}<0.007)$.

Compared with the pre-PCI level, the post-PCI CK-MB level did not significantly increase in the high-load group. Meanwhile, the CK-MB levels in the mid-load and high-load groups were significantly lower than that in the control group. The pre- and post-PCI cTnI levels were similar in the mid-load and high-load groups, and were significantly lower in the high-load group than in the control group. The post-PCI hs-CRP levels in all four groups were significantly higher than their respective pre-PCI levels, and were significantly lower in the high-load group than in the control and low-load groups. After PCI, the alanine aminotransferase (ALT) levels in all four groups were significantly higher than their respective pre-PCI levels (all $\mathrm{P}<0.05$ ), but remained within the normal range, except in one patient in the high-load group, and there were no significant differences among the four groups $(\mathrm{P}>0.05)$ (Table 5). 
TABLE 1

Main clinical features of patients in the four groups

\begin{tabular}{|c|c|c|c|c|}
\hline Variable & Control group $(n=20)$ & Low-load group $(n=20)$ & Mid-load group $(n=20)$ & High-load group $(n=20)$ \\
\hline Age, years & $60.80 \pm 7.52$ & $61.65 \pm 8.24$ & $61.90 \pm 6.40$ & $61.40 \pm 6.82$ \\
\hline Male sex & $12(60)$ & $14(70)$ & $13(65)$ & $11(55)$ \\
\hline Body mass index, $\mathrm{kg} / \mathrm{m}^{2}$ & $23.98 \pm 2.31$ & $24.26 \pm 2.27$ & $23.96 \pm 2.40$ & $24.50 \pm 2.40$ \\
\hline Hypertension & $12(60)$ & $10(50)$ & $11(55)$ & $12(60)$ \\
\hline Smokers & $6(30)$ & $7(35)$ & $8(40)$ & $8(40)$ \\
\hline Previous myocardial infarction & $1(5)$ & $0(0)$ & $0(0)$ & $0(0)$ \\
\hline Previous bypass surgery & $0(0)$ & $0(0)$ & $0(0)$ & $0(0)$ \\
\hline LVEF, \% & $56.00 \pm 9.75$ & $58.95 \pm 7.29$ & $55.25 \pm 8.41$ & $59.85 \pm 4.68$ \\
\hline LDL-C, mmol/L & $2.74 \pm 0.93$ & $2.83 \pm 1.09$ & $2.82 \pm 0.63$ & $2.78 \pm 0.63$ \\
\hline Triglycerides, $\mathrm{mmol} / \mathrm{L}$ & $2.00 \pm 1.25$ & $1.96 \pm 0.93$ & $1.82 \pm 0.67$ & $1.90 \pm 0.90$ \\
\hline Cholesterol, mmol/L & $4.94 \pm 1.03$ & $4.97 \pm 1.32$ & $4.66 \pm 0.98$ & $5.07 \pm 1.40$ \\
\hline $\mathrm{HDL}-\mathrm{C}, \mathrm{mmol} / \mathrm{L}$ & $1.19 \pm 0.47$ & $1.35 \pm 0.56$ & $1.30 \pm 0.56$ & $1.18 \pm 0.35$ \\
\hline Clopidogrel & $20(100)$ & $20(100)$ & $20(100)$ & $20(100)$ \\
\hline Beta-blockers & $14(70)$ & $15(75)$ & $14(70)$ & $14(70)$ \\
\hline ACEI/ARB & $15(75)$ & $15(75)$ & $16(80)$ & $14(70)$ \\
\hline GP IIb/IIla receptor inhibitors & $2(10)$ & $1(5)$ & $2(10)$ & $2(10)$ \\
\hline Unstable angina & $17(85)$ & $14(70)$ & $15(75)$ & $16(80)$ \\
\hline NSTEMI & $3(15)$ & $6(30)$ & $5(25)$ & $4(20)$ \\
\hline Multivessel coronary disease & $6(30)$ & $7(35)$ & $5(25)$ & $8(40)$ \\
\hline
\end{tabular}

Data presented as $n$ (\%) or mean \pm SD. ACEI/ARB Angiotensin-converting enzyme inhibitor or angiotension receptor blocker; GP Platelet glycoprotein; HDL-C Highdensity lipoprotein cholesterol; LDL-C Low-density lipoprotein cholesterol; LVEF Left ventricular ejection fraction; NSTEMI Non-ST segment elevation myocardial infarction

\section{TABLE 2}

\section{Procedural features in the four groups}

\begin{tabular}{|c|c|c|c|c|}
\hline Variable & Control group $(n=20)$ & Low-load group $(n=20)$ & Mid-load group $(n=20)$ & High-load group $(n=20)$ \\
\hline \multicolumn{5}{|l|}{ Vessels treated } \\
\hline Left main artery & $0(0)$ & $0(0)$ & $0(0)$ & $0(0)$ \\
\hline Left anterior descending artery & $8(40)$ & $10(50)$ & $8(40)$ & $7(35)$ \\
\hline Left circumflex artery & $6(30)$ & $7(35)$ & $7(35)$ & $9(45)$ \\
\hline Right coronary artery & $10(50)$ & $7(35)$ & $8(40)$ & $9(45)$ \\
\hline Multivessel intervention & $4(20)$ & $4(20)$ & $3(15)$ & $5(25)$ \\
\hline Number of stents & $1.60 \pm 0.68$ & $1.50 \pm 0.69$ & $1.45 \pm 0.60$ & $1.55 \pm 0.76$ \\
\hline Stent diameter, mm & $4.89 \pm 1.90$ & $4.61 \pm 1.96$ & $4.38 \pm 1.71$ & $4.50 \pm 2.57$ \\
\hline Total length, mm & $29.50 \pm 13.74$ & $32.10 \pm 13.55$ & $31.00 \pm 14.28$ & $29.25 \pm 14.48$ \\
\hline Stent deployment pressure, atm & $21.05 \pm 11.05$ & $21.00 \pm 11.49$ & $21.15 \pm 11.37$ & $22.70 \pm 11.07$ \\
\hline Duration of stent deployment, s & $8.00 \pm 3.40$ & $7.50 \pm 3.44$ & $7.25 \pm 3.02$ & $7.75 \pm 3.80$ \\
\hline Use of postdilation procedure & $2(10)$ & $2(10)$ & $3(15)$ & $1(5)$ \\
\hline
\end{tabular}

Data presented as $n(\%)$ or mean $\pm S D$

No gastrointestinal reactions (eg, nausea and vomiting), myalgia or myasthenia were observed. One patient in the high-load group had an ALT level beyond the upper limit of the normal range, but by less than $300 \%$. In this patient, atorvastatin treatment was continued and, after treatment with diisopropylamine dichloroacetate, the ALT level decreased to within the normal range.

\section{DISCUSSION}

PCI-induced myocardial damage does not result in clear clinical symptoms, changes in electrocardiogram readings or effects on cardiac functions; instead, such damage may only appear as an increase in myocardial marker levels. However, such damage is associated with increased rates of MACE (6). Many recent studies have shown that short-term loading of statins has beneficial pleiotropic cardiovascular effects, which are independent of their lipid-lowering effects $(7,8)$ because statins can only lower the lipid level with long-term treatment. The effects of statins include protection of the endothelium (9), dilation of coronary microvessels (10), reduction of thrombogenesis (11), antiplatelet and anti-inflammatory capabilities (12), and significant lowering of post-PCI intercellular adhesion molecule-1 and E-selectin levels (13). Animal studies have also shown that acute statin loading before reperfusion reduced the area of myocardial infarction (14).

Clinical trials, including Myocardial Ischemia Reduction with Aggressive Cholesterol Lowering (MIRACL) (15) and Pravastatin or Atorvastatin Evaluation and Infection Therapy (PROVE-IT) (16), have confirmed that early treatment of ACS patients with high-dose statins can reduce the incidence of cardiovascular events. 
TABLE 3

The incidence of primary end points at one month in the four groups

\begin{tabular}{lcccc}
\hline & $\begin{array}{c}\text { Control } \\
\text { group }\end{array}$ & $\begin{array}{c}\text { Low-load } \\
\text { group }\end{array}$ & $\begin{array}{c}\text { Mid-load } \\
\text { group }\end{array}$ & $\begin{array}{c}\text { High-load } \\
\text { group }\end{array}$ \\
\hline Cardiac death & 0 & 0 & 0 & 0 \\
Myocardial infarction & $8(40)$ & $5(25)$ & $2(10)$ & $0(0)^{\star \dagger}$ \\
Target-vessel revascularization & 0 & 0 & 0 & 0 \\
Total MACE & $8(40)$ & $5(25)$ & $2(10)$ & $0(0)^{* \dagger}$ \\
\hline Dita
\end{tabular}

Data presented as $n(\%) .{ }^{*}$ The rate compared with the control group was significantly different $(P<0.007) ;{ }^{\dagger}$ The four groups were significantly different $(P<0.05)$. MACE Major adverse cardiac events

In the ARMYDA-ACS trial (3), patients with NSTE-ACS who underwent PCI within $48 \mathrm{~h}$ of admission were treated with atorvastatin $(80 \mathrm{mg}$ and $40 \mathrm{mg}$ atorvastatin at $12 \mathrm{~h}$ and $2 \mathrm{~h}$ before PCI, respectively) or placebo. The results revealed that pre-PCI loading with atorvastatin reduced the incidence of myocardial damage. The subsequent ARMYDA-RECAPTURE trial (4) studied the effect of atorvastatin in patients with stable angina or NSTE-ACS. In that study, patients underwent PCI after treatment with statins for at least 30 days, and were given atorvastatin $(80 \mathrm{mg}$ and $40 \mathrm{mg}$ at $12 \mathrm{~h}$ and $2 \mathrm{~h}$ before PCI, respectively) or placebo. Similarly, that trial found that pre-PCI treatment with atorvastatin significantly reduced myocardial damage.

In China, most NSTE-ACS patients only start statin therapy during an in-hospital stay and undergo PCI after appropriate examinations (generally two to three days after admission). The optimum dose and frequency of atorvastatin treatment in this patient group have not been formally evaluated. In the present study, we compared the myocardial effects of short-term atorvastatin treatment before PCI at four loading doses. Our findings confirm that, in these patients, the incidence of myocardial damage and inflammatory reactions decreased with increasing dose and frequency of atorvastatin administration. Our findings differ from those of the ARMYDARECAPTURE trial in that the mid-load dose $(80 \mathrm{mg}$ atorvastatin $12 \mathrm{~h}$ before PCI plus $40 \mathrm{mg}$ atorvastatin $2 \mathrm{~h}$ to $4 \mathrm{~h}$ before $\mathrm{PCI}$ ) was associated with a lower incidence of MACE compared with the control group (although, the difference was not statistically significant in our study), and that the high-load dose ( $80 \mathrm{mg}$ atorvastatin $12 \mathrm{~h}$ before PCI plus $60 \mathrm{mg}$ atorvastatin $2 \mathrm{~h}$ to $4 \mathrm{~h}$ before PCI) seemed to
TABLE 4

Influence of percutaneous coronary intervention (PCI) on myocardial markers in the four groups

\begin{tabular}{lcccc}
\hline & $\begin{array}{c}\text { Control } \\
\text { group }\end{array}$ & $\begin{array}{c}\text { Low-load } \\
\text { group }\end{array}$ & $\begin{array}{c}\text { Mid-load } \\
\text { group }\end{array}$ & $\begin{array}{c}\text { High-load } \\
\text { group }\end{array}$ \\
\hline The proportion of patients with pre-PCl cardiac & marker elevation above ULN \\
CK-MB & $3(15)$ & $5(25)$ & $4(20)$ & $3(15)$ \\
cTnl & $3(15)$ & $6(30)$ & $5(25)$ & $4(20)$ \\
The proportion of patients with post-PCl cardiac & marker elevation above ULN \\
CK-MB & $15(75)^{*}$ & $10(50)$ & $9(45)$ & $5(25)^{\dagger}$ \\
cTnl & $16(80)^{*}$ & $12(60)$ & $9(45)$ & $7(35)^{\dagger \ddagger}$ \\
\hline
\end{tabular}

Data presented as $n$ (\%). *The rate compared with pre-PCI was significantly different $(P<0.05)$; ${ }^{\dagger}$ The rate compared with the control group was significantly different $(P<0.007) ;{ }^{\ddagger}$ The four groups were significantly different $(P<0.05)$. CK-MB Creatine kinase-MB; CTnI Cardiac troponin I; ULN Upper limit of normal

be more effective for this patient group. The differences may be attributed to the length of atorvastatin treatment before PCI and the sample size. Nevertheless, dose-dependent antiplatelet and antiinflammatory effects of atorvastatin have been demonstrated (17). For ACS patients, the thrombogenesis and inflammatory reactions are closely related to the PCI-related myocardial damages, and our results indicate that a high dose of atorvastatin should be given before PCI.

The incidence of transaminase elevations during statin therapy was reported to be approximately $1 \%$ to $2 \%$. These elevations usually occurred within the first three months of treatment in a dose-dependent manner, and could be restored to the baseline level by reducing the statin dose or discontinuing statin treatment (18). The maximum shortterm pre-PCI loading dose was $120 \mathrm{mg}$ in the ARMYDA studies, and no clear adverse reactions were observed. Similarly, the study by Ge et al (19) showed that $80 \mathrm{mg}(12 \mathrm{~h}$ pre-PCI) and $40 \mathrm{mg}$ ( $2 \mathrm{~h}$ pre-PCI) of atorvastatin was well tolerated in Asian patients with NSTE-ACS and reduced the incidence of MACE. However, other studies (20) do not support high doses of statins, particularly rosuvastatin, in Asian populations. The doses currently recommended for statins are effective only for lowering blood lipid levels, and the appropriate dose for myocardial protection during the peri-PCI period remains unclear. Therefore, in the present study, we explored the effects of higher loading doses on preventing myocardial damage. The highest pre-PCI dose was $140 \mathrm{mg}$ in the high-load group ( $80 \mathrm{mg} 12 \mathrm{~h}$ before PCI plus $60 \mathrm{mg} 2 \mathrm{~h}$ to $4 \mathrm{~h}$ before

TABLE 5

The changes of marker levels

\begin{tabular}{|c|c|c|c|c|}
\hline & Control group & Low-load group & Mid-load group & High-load group \\
\hline \multicolumn{5}{|l|}{ CK-MB, ng/mL } \\
\hline pre-PCl & $12.65 \pm 5.75$ & $13.05 \pm 6.61$ & $13.90 \pm 5.25$ & $13.35 \pm 8.18$ \\
\hline $8 \mathrm{~h}$ post- $\mathrm{PCl}$ & $16.65 \pm 5.17^{*}$ & $16.25 \pm 6.36$ & $16.05 \pm 5.99$ & $15.35 \pm 8.30$ \\
\hline \multicolumn{5}{|l|}{ cTnl, ng/mL } \\
\hline Pre-PCl & $0.40 \pm 0.78$ & $0.41 \pm 0.78$ & $0.46 \pm 0.91$ & $0.42 \pm 0.74$ \\
\hline $8 \mathrm{~h}$ post- $\mathrm{PCl}$ & $1.12 \pm 0.84^{*}$ & $1.09 \pm 1.08^{*}$ & $0.91 \pm 1.11$ & $0.74 \pm 0.83$ \\
\hline \multicolumn{5}{|l|}{ hs-CRP, mg/L } \\
\hline Pre-PCl & $4.39 \pm 1.01$ & $4.24 \pm 0.97$ & $4.04 \pm 0.94$ & $4.07 \pm 1.37$ \\
\hline $8 \mathrm{~h}$ post- $\mathrm{PCl}$ & $7.78 \pm 2.29^{*}$ & $7.51 \pm 2.08^{*}$ & $7.50 \pm 2.16^{\star}$ & $6.18 \pm 2.28^{\star \dagger}$ \\
\hline 24 h post- $\mathrm{PCl}$ & $10.98 \pm 2.62^{*}$ & $10.08 \pm 3.05^{\star}$ & $9.59 \pm 3.13^{*}$ & $7.78 \pm 2.86^{\star \dagger \ddagger}$ \\
\hline \multicolumn{5}{|l|}{ ALT, U/L } \\
\hline Pre-PCl & $16.00 \pm 3.98$ & $16.95 \pm 2.56$ & $16.55 \pm 3.05$ & $17.35 \pm 3.34$ \\
\hline
\end{tabular}

Data presented as mean $\pm S D .{ }^{*}$ Postpercutaneous coronary intervention $(P C l)$ compared with pre-PCl was significantly different $(P<0.05) ;{ }^{\dagger}$ The level compared with the control group was significantly different $(P<0.05)$; ${ }^{\ddagger}$ The level compared with the low-load group was significantly different $(P<0.05)$. ALT Alanine aminotransferase; CK-MB Creatine kinase-MB; cTnI Cardiac troponin I; hs-CRP Highly sensitive C-reactive protein 
PCI). We also evaluated the benefits and risks. Significant elevations in transaminase levels occurred after PCI in all four groups, but with similar magnitudes, and were within the upper limit of the normal range. No patient experienced myalgia or myasthenia. These observations indicate that high-dose pre-PCI atorvastatin therapy may temporarily increase the workload on the liver and result in a transient elevation of the transaminase level, but this elevation can be reversed by discontinuing the atorvastatin loading, suggesting that the benefits outweigh the potential risks.

In summary, our study revealed that pre-PCI loading with statins may reduce the incidence of $\mathrm{PCI}$-induced myocardial damage, and that these beneficial myocardial effects increased with increasing dose and frequency of statin loading. This loading treatment might be associated with relatively mild adverse reactions and be well tolerated. The present study suggests that different pre-PCI loading protocols may be used clinically depending on the specific conditions of the patient. The limitations of the present study include a relatively small sample size and the discontinuous observation of indicators after PCI. Larger-scale controlled, randomized trials with extended monitoring of PCI indexes are needed to confirm the clinical efficacy of this approach.

\section{REFERENCES}

1. Ellis SG, Chew D, Chan A, et al. Death following creatine kinase-MB elevation after coronary intervention: Identification of an early risk period: Importance of creatine kinase-MB level, completeness of revascularization, ventricular function, and probable benefit of statin therapy. Circulation 2002;106:1205-10.

2. Pasceri V, Patti G, Nusca A, et al. ARMYDA Investigators. Randomized trial of atorvastatin for reduction of myocardial damage during coronary intervention: Results from the ARMYDA (Atorvastatin for Reduction of Myocardial Damage During Angioplasty) study. Circulation 2004;110:674-8.

3. Patti G, Pasceri V, Colonna G, et al. Atorvastatin pretreatment improves outcomes in patients with acute coronary syndromes undergoing early percutaneous coronary intervention: Results of the ARMYDA-ACS randomized trial. J Am Coll Cardiol 2007;49:1272-8.

4. Di Sciascio G, Patti G, Pasceri V, Gaspardone A, Colonna G, Montinaro A. Efficacy of atorvastatin reload in patients on chronic statin therapy undergoing percutaneous coronary intervention: Results of the ARMYDA-RECAPTURE (Atorvastatin for Reduction of Myocardial Damage During Angioplasty) Randomized Trial. J Am Coll Cardiol 2009;54:558-65.

5. Thygesen K, Alpert JS, White HD, on behalf of the Joint ESC/ ACCF/AHA/WHF Task Force for the Redefinition of Myocardial Infarction. Universal definition of myocardial infarction. J Am Coll Cardiol 2007;50:2173-95.

6. Nallamothu BK, Bates ER. Periprocedural myocardial infarction and mortality: causality versus association. J Am Coll Cardiol 2003;42:1412-4.
7. Ray KK, Cannon CP, Ganz P. Beyond lipid lowering: What have we learned about the benefits of statins from the acute coronary syndomes trials? Am J Cardiol 2006;98:S18-25.

8. Calabro P, Yeh ET. The pleiotropic effects of statins. Curr Opin Cardiol 2005;20:541-6.

9. Wassmann S, Faul A, Hennen B, et al. Rapid effect of 3-hydroxy-3-methylglutaryl coenzyme A reductase inhibition on coronary endothelial function. Circ Res 2003;93:e98-103.

10. Hinoi T, Matsuo S, Tadehara F, et al. Acute effect of atorvastatin on coronary circulation measured by transthoracic Doppler echocardiography in patients without coronary artery disease by angiography. Am J Cardiol 2005;96:89-91.

11. Sanguigni V, Pignatelli P, Lenti L, et al. Short-term treatment with atorvastatin reduces platelet CD40 ligand and thrombin generation in hypercholesterolemic patients. Circulation 2005;111:412-9.

12. Macin SM, Perna ER, Farias EF, et al. Atorvastatin has an important acute anti-inflammatory effect in patients with acute coronary syndrome: Results of a randomized, double-blind, placebo-controlled study. Am Heart J 2005;149:451-7.

13. Patti G, Chello M, Pasceri V, et al. Protection from procedural myocardial injury by atorvastatin is associated with lower levels of adhesion molecules after percutaneous coronary intervention: Results from the RMYDA-CAMs (Atorvastatin for Reduction of Myocardial Damage during Angioplasty-Cell Adhesion Molecules) substudy. J Am Coll Cardiol 2006;48:1560-6.

14. Bell RM, Yellon DM. Atorvastatin, administered at the onset of reperfusion, and independent of lipid lowering, protects the myocardium by up-regulating a pro-survival pathway. J Am Coll Cardiol 2003;41:508-15.

15. Schwartz GG, Olsson AG, Ezekowitz MD, et al. Effects of atorvastatin on early recurrent ischemic events in acute coronary syndromes: The MIRACL Study. A randomized controlled trial. JAMA 2001;285:1711-8.

16. Cannon CP, I Braunwald E, McCabe C, et al. Intensive versus moderate lipid lowering with statins after acute coronary syndromes. N Eng J Med 2004;350:1495-504.

17. Piorkowski M, Fischer S, Stellbaum C, et al. Treatment with ezetimibe plus low-dose atorvastatin compared with higher-dose atorvastatin alone: Is sufficient cholesterol-lowering enough to inhibit platelets? J Am Coll Cardiol 2007;49:1035-42.

18. National Cholesterol Education Program (NCEP) Expert Panel on Detection, Evaluation, and Treatment of High Blood Cholesterol in Adults (Adult Treatment Panel III). Third Report of the National Cholosterol Education Program (NCEP) Expert Panel on Detection, Evaluation, and Treatment of High Blood Cholesterol in Adults (Adult Tteatment Panel III) final report. Circulation 2002;106:3143-421.

19. Ge J, Kin YJ, Jang YS, et al. Design and rationale of a study in Asia of atorvastatin pretreatment in patients undergoing percutaneous coronary intervention for non-ST elevation acute coronary syndromes. J Cardiol 2010;55:303-8.

20. Liao JK. Safety and efficacy of statins in Asians. Am J Cardiol 2007;99:410-4 